Chemistry and Technology of Fuels and Oils, Vol. 42, No.3, 2006

\title{
RECIPROCAL INFLUENCE OF CRYSTALLIZATION AND VITRIFICATION PROCESSES IN COMPLEX HYDROCARBON SYSTEMS
}

\author{
V. G. Kucherov and A. I. Chernoutsan
}

UDC 665.61.085:543.422.4

The results of an experimental study of crystallization and glass transition of Kumkol' crude in a wide range of pressures and temperatures are reported in [1], concerning the critical properties of petroleum systems. This crude is a characteristic representative of low-viscosity crudes with a high wax content. It was shown that crystallization of the waxes, which takes place when the temperature is decreased or the pressure is increased, does not prevent further glass transition of the fractions remaining in the liquid state.

Crystallization and glass transition can be successively observed in complex multicomponent systems. In systems of simpler composition (one-component or low-molecular-weight), the glass transition takes place only if transition of the system to the crystalline state can be avoided until the glass transition ends, which is attained at a sufficiently rapid cooling rate. In this case, the system cannot pass from the metastable liquid state to the stable crystalline state. If crystallization takes place in a simple system, it occupies the entire volume of the sample and the liquid phase disappears, so that the glass transition becomes impossible.

In complex high-molecular-weight (polymer, for example) systems, on the contrary, crystallization can be so difficult that the system remains amorphous even at a low cooling rate. Such a "truly amorphous" system passes into the glassy state on cooling without preliminary crystallization.

We can hypothesize that the petroleum systems we studied belong to the class of complex multicomponent systems whose critical properties are satisfactorily described with the following model. We will show that such a system consists of a high-molecular-weight amorphous matrix in which easily crystallized components of different molecular weight and composition are dissolved. On cooling the sample (or increasing the pressure), these components begin to crystallize. The process takes place in a wide range of temperatures, and each component is crystallized in its own narrow temperature range.

Since each crystallizable component constitutes a low mass fraction of the substance, its crystals do not occupy the entire volume of the sample. They form small clusters inside the liquid phase consisting of an amorphous matrix and not yet crystallized components. The glass transition of the amorphous high-molecular-weight matrix then takes place, and the presence of crystalline disseminations does not prevent this. The glass transition can begin both before and after completion of crystallization.

I. M. Gubkin Russian State University of Oil and Gas. Translated from Khimiya i Tekhnologiya Topliv $i$ Masel, No. 3, pp. 36-38, May-June, 2006. 
Table 1

\begin{tabular}{|c|c|c|}
\hline \multirow{2}{*}{ Indexes } & \multicolumn{2}{|c|}{ Crude } \\
\hline & North Komsomol'sk & Kumkol' \\
\hline Density at $20^{\circ} \mathrm{C}, \mathrm{kg} / \mathrm{m}^{3}$ & 942 & 813 \\
\hline Molecular weight & 305 & 225 \\
\hline Initial boiling point, ${ }^{\circ} \mathrm{C}$ & 207 & 20 \\
\hline Viscosity at $50^{\circ} \mathrm{C}, \mathrm{mm}^{2} / \mathrm{sec}$ & 80,9 & 3,7 \\
\hline \multicolumn{3}{|l|}{ Content, $\%$} \\
\hline silica gel resins & 14 & 10 \\
\hline asphaltenes & 1,3 & $<0,1$ \\
\hline waxes & 0,2 & 15 \\
\hline water & \multicolumn{2}{|c|}{ absent } \\
\hline \multicolumn{3}{|l|}{ Distillation, vol. \% } \\
\hline under $100^{\circ} \mathrm{C}$ & 0 & 8 \\
\hline under $200^{\circ} \mathrm{C}$ & 0 & 28 \\
\hline under $300^{\circ} \mathrm{C}$ & 11 & 50 \\
\hline
\end{tabular}

If crystallization and glass transition in complex multicomponent systems takes place as described, then we can hypothesize that a change in the composition of crystallizable components with retention of the same amorphous matrix should markedly affect the crystallization process but not significantly affect the glass transition process. To test this hypothesis, the following were performed: measurements of the thermophysical characteristics of two heavy fractions of Kumkol' crude with a different composition of the crystallizable components; comparison of the critical properties of North Komsomol'sk crude, which contains no waxes and does not vitrify, and a model petroleum system.

The physicochemical properties of degassed and dehydrated samples of North Komsomol'sk and Kumkol' crudes are reported in Table 1. North Komsomol'sk crude is much more viscous than Kumkol' crude. In addition, it contains almost no waxes.

It was experimentally shown in $[2,3]$ that in crudes of the North Komsomol'sk type, there is no crystallization region, but then glass transition takes place at comparatively high temperatures and low pressures. On the contrary, in Kumkol' crude [1], the wax crystallization region is very pronounced, but the glass transition is much more difficult to observe, since it takes place at much lower temperatures and higher pressures.

The samples used to test the hypothesis concerning the independence of glass transition of the liquid amorphous matrix from the wax content and composition are described below:

- sample 1 - the heavy cut of Kumkol' crude, a mixture of cuts distilling above $250^{\circ} \mathrm{C}$, with viscosity of $28.3 \mathrm{~mm}^{2} / \mathrm{sec}$ at $100^{\circ} \mathrm{C}$;

- sample 2 - the heavy cut of Kumkol' crude with no resins, asphaltenes, and waxes obtained from sample 1 by removal of: resins and asphaltenes - by the standard method of deasphalting and deresination; waxes - by the standard method of low-temperature dewaxing;

- sample 3 - Kumkol' crude waxes; 


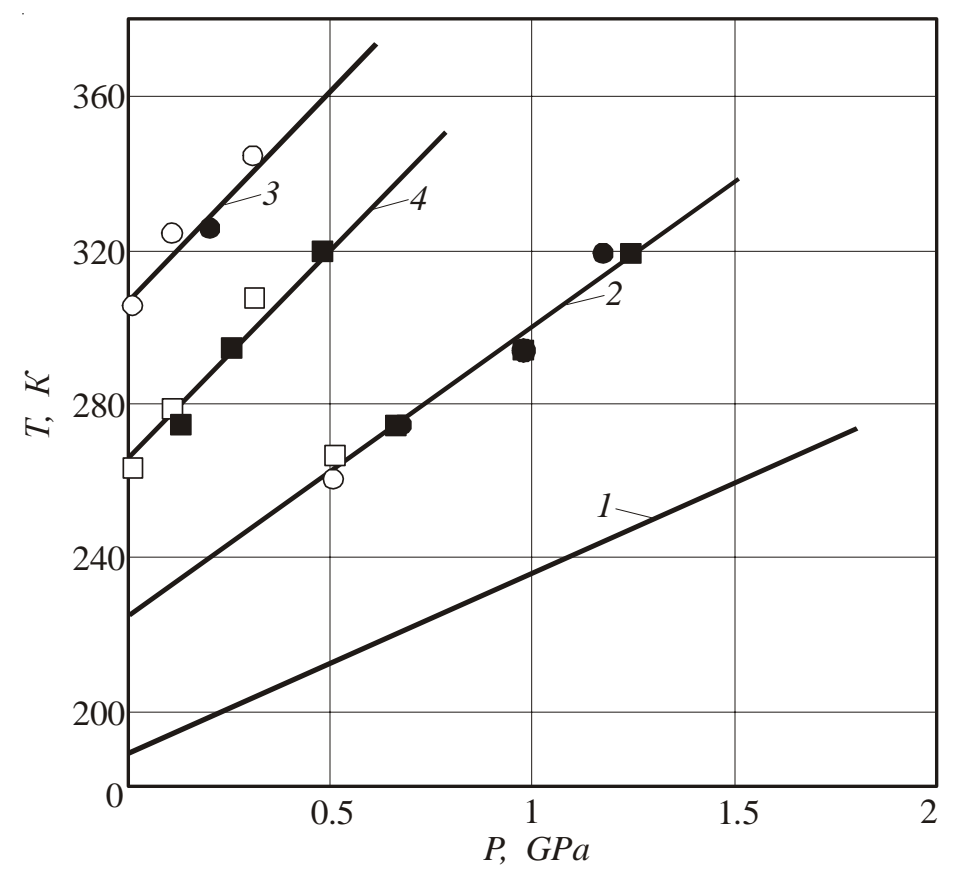

Fig. 1. Phase diagram: 1,2) glass transition line of Kumkol' crude and its heavy fractions - samples 1 and $2 ; 3,4)$ line of onset of crystallization of samples $1(\mathrm{O}, \bullet)$ and $2(\square, \boldsymbol{\square}) ; \bigcirc, \square$-with an isobaric change in the temperature; $\bullet, \mathbf{\square}$ - with an isothermal change in the pressure.

- sample 4 - a model system which is a mixture of North Komsomol'sk crude with Kumkol' crude waxes (sample 3) obtained by dissolving $10 \mathrm{wt}$. \% waxes in a closed container at $70^{\circ} \mathrm{C}$.

The critical properties of the crudes and their cuts were investigated at the base of the Faculty of Experimental Physics at the University in Umea (Sweden) in a joint project by Professor G. Backstrem's group and the I. M. Gubkin Russian State University of Oil and Gas.

The heat capacity per unit volume $\rho c_{p}$ and thermal conductivity $\lambda$ were measured with the heated filament method along five isotherms (at 249, 295, 320, 353, and $373 \mathrm{~K}$ ) at pressures of under $2 \mathrm{GPa}$ and along five isobars (at $0,0.1,0.3$, and $0.5 \mathrm{GPa}$ ) at temperatures of $250-370 \mathrm{~K}$. In the isothermal measurements, the temperature was stabilized after each step with respect to the pressure. In the isobaric measurements, the temperature was increased at a constant rate of $0.01 \mathrm{~K} / \mathrm{sec}$. The temperature elevation of the nickel wire in each measurement event was approximately $2 \mathrm{~K} / \mathrm{sec}$ (temperature elevation rate of the order of $1 \mathrm{~K} / \mathrm{sec}$ ). As demonstrated in [4], convective effects can be neglected for viscous liquids in these conditions.

DSC measurements of the specific heat $c_{p}$ at atmospheric pressure using a standard Perkin-Elmer DSC-2 calorimeter calibrated with standard substances were performed to control the results obtained [5]. To ensure complete dissolution of precipitated hydrocarbons, the samples were held in closed containers at $340 \mathrm{~K}$ for $15 \mathrm{~min}$ and then shaken.

They were then cooled to room temperature and placed in standard aluminum capsules. After heating the samples in the calorimeter to $340 \mathrm{~K}$, the measurements were begun in the cooling mode. The measurements were performed in the 130-340 $\mathrm{K}$ range. The rate of the change in the temperature both in heating and in cooling was $10 \mathrm{~K} / \mathrm{min}$. All measurements were performed three times with a maximum error of $2 \%$. 

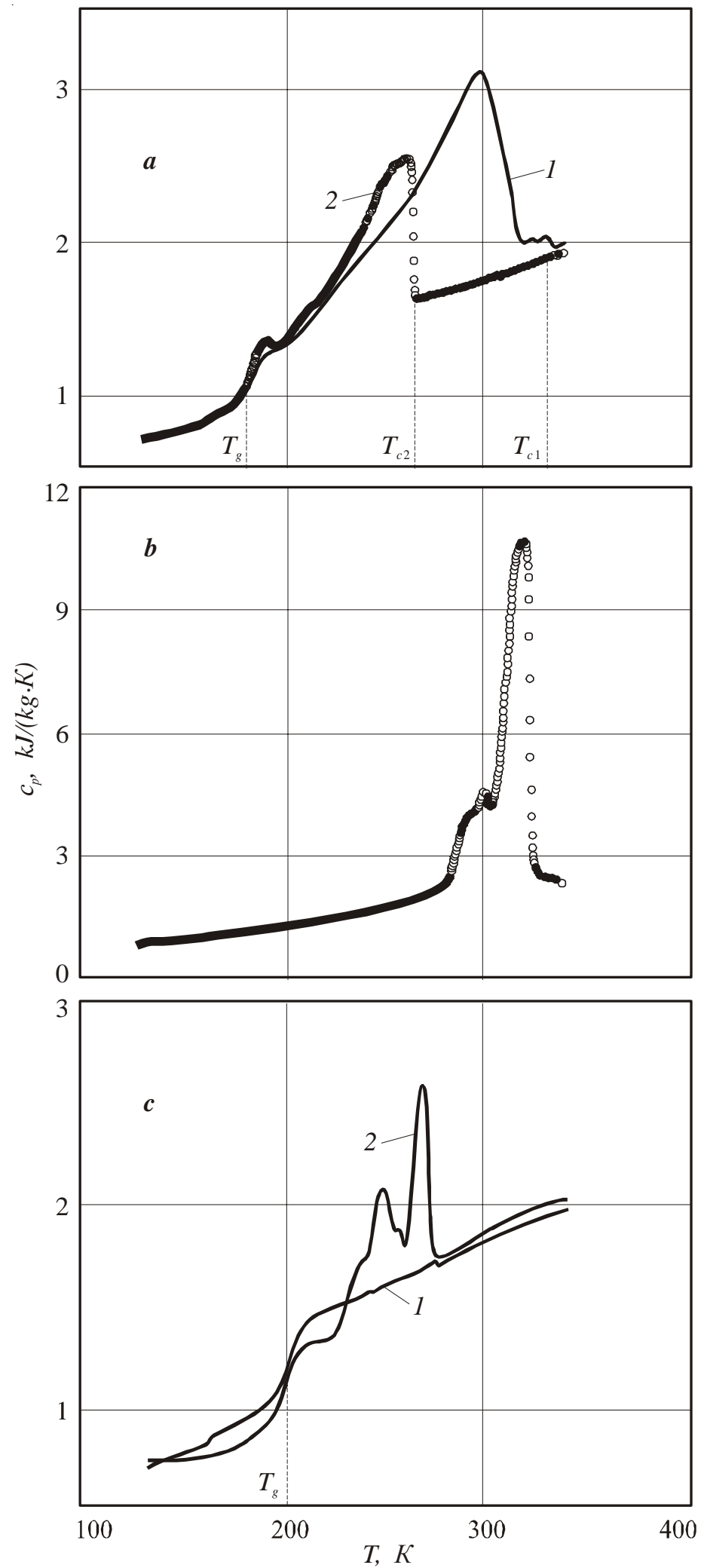

Fig. 2. Calorimetric data: a) for heavy cuts - samples 1 (curve 1) and 2 (curve 2); b) for Kumkol' crude waxes - sample 3; c) for North Komsomol'sk crude (curve 1) and the model system - sample 4 (curve 2, glass transition point $T_{g}$ did not change when waxes were added). 
The results of the study of samples 1 and 2 obtained with the heated filament method are shown in Fig. 1. For comparison, the glass transition line of Kumkol' crude is also shown there. Two critical regions corresponding to crystallization and glass transition were observed for each sample both for an isothermal change in the pressure (dark points) and for an isobaric change in the temperature (light points).

Both samples, despite the different composition, have the same glass transition line, which also confirms the hypothesis concerning the independence of the glass transition process in petroleum systems from their wax content, like other easily crystallized components.

A similar hypothesis was also advanced previously in [6], but it was not convincingly substantiated experimentally, since different petroleum systems with similar properties and composition were investigated. Our results were obtained for the same hydrocarbon matrix.

The invariability of the position of the glass transition line indicates that the hydrocarbon matrix of this petroleum system does not change when waxes, asphaltenes, and resins are extracted. In other words, we can conclude: the presence and composition of the crystalline clusters in the hydrocarbon matrix do not affect the glass transition process.

The results of the calorimetric measurements (Fig. 2a) completely confirmed the results obtained with the heated filament method. It is clear that the glass transition temperatures $T_{g}$ of the two cuts are the same at atmospheric pressure, while the initial crystallization point $T_{c 2}$ of sample 2 is shifted by more than $50 \mathrm{~K}$ toward lower temperatures relative to the same point $T_{c 1}$ for sample 1 .

Calorimetric studies of the model system (sample 4) at atmospheric pressure in the 130-370 K temperature range were conducted to additionally confirm the independence of the crystallization and glass transition processes in petroleum systems. Sample 3 used for preparation of sample 4 (Kumkol' crude waxes) was first tested in the calorimeter (Fig. 2b). The measurements confirmed the existence of the crystallization process in a narrow temperature range and the absence of the glass transition process.

The results of the study of the model system presented in Fig. 2c show that addition of waxes alters the overall picture of the phase behavior of North Komsomol'sk crude. Crystallization was observed in sample 4, while it did not occur in the North Komsomol'sk crude itself. It is natural to hypothesize that the added waxes crystallized in this sample. The experimental data also indicate that the appearance of crystallization in no

way affects the glass transition process. Crystallization in the model system takes place at lower temperatures in comparison to crystallization of waxes.

\section{REFERENCES}

1. V. G. Kucherov and A. I. Chernoutsan, Khim. Tekhnol. Topl. Masel, No. 6, 16-1 (2001).

2. V. Kutcherov, A. Lundin, R. G. Ross, et al., Int. J. Thermophys., 15, 165-176 (1994).

3. V. Kutcherov, G. Bäckström, M. Anisimov, et al., J. Phys. E. Sci. Instr., 10, 474-477 (1977).

4. O. Sandberg, P. Andersson, and G. Bäckström, J. Phys. E. Sci. Instr., 10, 474-477 (1977).

5. P. Skoglunmd and A. Fransson, Thermochim. Acta, 276, 27-39 (1996).

6. P. Claudy, J. M. Letoffé, B. Chagué, et al., Fuel, 67, 58-61 (1988). 